\title{
The development of an Android Applications Model for the Smart Micro-Grid Power Pool System Monitoring and Control
}

\author{
Kufre Esenowo Jack, Damian Obioma Dike, Jude-Kennedy C. Obichere, Matthew Olubiwe
}

\begin{abstract}
This paper presents the conceptual Android Applications Model for the Smart Micro-Grid Power Pool Monitoring and Control Scheme. The Rational for Energy Sustainability is the focus of this work. Several hybrid formations are utilized on either standalone or off grid basis without formidable measures to monitor and control the system against energy wastage remotely. This research work proposed smart micro-grid integrated scheme with android enable operated softtouch human machine interface for the remote monitoring and control of the hybrid power pool system with its load shedding capability for Energy Sustainability. The optimize hybridized renewable energy resources harvested from the abundant wind, sun, water and bio-resources with the grid and Generator sources from Afikpo Local Government Area of Ebonyi State was considered as a research focal point. Proteus was used in designing system circuitries for the control and monitoring of the power pool system to ascertain its functionability. Arduino IDE was used in developing, monitoring and control algorithm for the system operation. The sublime text enables HTML, JAVA and CSS program for the android application implementation. The design provides a remote operated touch screen Human Machine interface for the pool resources to be centrally manage or control thus, eliminating energy wastage. Five communities where selected for this demonstration. The results reveal that the android enable remote soft touch human machine interface facilitates optimal energy operation. Further research work should be tailored towards developing a similar scheme using same approach for up to 10 communities in the similar local government areas to face out energy sabotage.
\end{abstract}

Keyword: - Android Applications, Human Machine Interface (HMI), Arduino, Power Pool System, Hybridized Energy System and Smart Micro-Grid

\section{INTRODUCTION}

The quest for the lasting solution to insufficient energy supply through research and technological advancement will not end until one megawatt of electricity is made available for one household.

Revised Manuscript Received on February 05, 2020.

* Correspondence Author

Engr. Kufre Esenowo Jack, Department of Mechatronics Engineering, School of Electrical Engineering \& Technology, Federal University of Technology Minna, Nigeria. E-mail: kufre@futminna.edu.ng

Engr. Prof. Damian Obioma Dike, Department of Electrical/Electronics Engineering, School of Electrical Engineering \& Technology, Federal University of Technology Owerri, Imo State, E-mail: damian.dike@futo.edu.ng

Engr. Dr. Jude-Kennedy C. Obichere, Department of Mechatronics Engineering, School of Electrical Engineering \& Technology, Federal University of Technology Owerri, Imo State E-mail: judekennedyobichere@yahoo.com

Engr. Dr. Matthew Olubiwe, Department of Electrical/Electronics Engineering, School of Electrical Engineering \& Technology, Federal University of Technology Owerri, Imo State E-mail: olubiwe@yahoo.com

(C) The Authors. Published by Blue Eyes Intelligence Engineering and Sciences Publication (BEIESP). This is an open access article under the CC BY-NC-ND license (http://creativecommons.org/licenses/by-nc-nd/4.0/)
Several efforts have been made, though some of the already existing energy resources that are standalone need to be combined and recombined to optimal and efficient use. Few systems already hybridized required integration into microgrid system. [1] developed an Efficient Industrial Electrification system from an optimized Hybrid Renewable Energy resource which can be adopted for the rural community application. These rural Community electrification in its micro-grid form required adequate management criteria. In that, some communities have this renewable more than others without adequate harnessing it to its full potentials. Wastage of energy is also a factor this research intends to resolve. Remotely enable human Machine Interface has to be developed to manage or control this hybridized power pool system conceptual ideas via android apps. In Nigeria for example, Ebonyi State has in abundance some commercial energy resources. These energy resources are not uniformly distributed in term of form and location but nearby location seems to has a close related resource that can be harnessed. These will foster zonal, district cooperation and integration by energy pooling. This will minimize the cost of supply, wastages of energy as well as a result of economies of scale [2]. Recently, Java scripts, HTML and CSS has become the most general-purpose high programing language in that it is both event driven and object oriented. These developments have the potentials of providing the desktop Graphical Users Interface like its PLC counterpart. To affirm its uncommon application in control and automation, it is encapsulated into its features the websites and web applications. The people and technology interaction have enhanced though industrial operation in many areas. The Electromagnet water filter system was using Raspberry $\mathrm{Pi}$ and human machine interface was developed to ascertain its performance. It is on this note that the programme code interface was displayed on a soft-touch-screen. This allows user to input the system mode run times and as well determine the number of cycles each process should repeat [3].

\section{RELATED LITERATURES}

There is no doubt that python can also be used to develop a human machine interface for the control of power system and allies' applications. This is because similar software was experimented and proven by Simulation of the operation Interface of Hybrid Energy System using Laboratory Virtual Instrument Engineering Workbench (LabVIEW) and Simulink. The LabVIEW is a system-design platform developed with visual programming language from National Instrument [4]. Renewable energy is inexhaustible energy with advantages of cleanliness, sufficiency and recyclable in nature. 
Harnessing energy and allowing it to waste does not encourage economic growth. The integration of the electricity generated by several renewable sources to a centralized point engenders economic growth and eliminate wastages. This has been a practice in Europe before now but on a large scale to the level of intercontinental exchange of power. Our nations are to implement even at community level[5]. [6] and [7] reviewed some optimized hybridized renewable energy resources and provide a progressive data on the status of renewable energy in the present markets. The emphasis was placed on the potentials of combining numerous sources of energy into a hybrid renewable energy system. The advantages of hybridizing different systems help in overcoming limitations mated on the individual generating system due to its economics nature, reliability, flexibility and abundantly availability. [8] advocated for Hybrid energy system as a solution for remote / rural electrification with the interconnection in a micro-grid scenario. The research was on the different components of hybrid energy system. A generalized model was developed which supported the optimal combination of energy components for a typical rural community usage. This helps minimize the life cycle cost. The developed model aids hybrid energy system sizing of the hardware with renewables energy option selection techniques capabilities. For some decade, Power Pool system has been in the market with one challenge or the other. The prime aim of the pool system was to provide a reliable and economic supply of energy to their clients. The Intelligent Systems Reliability Assessment show that the market is becoming more concentrated; the Loss of load expectation will reduce, whereas the reliability will improve. Similarly, whenever the price elasticity of demand rises, the Loss of load expectation will reduce. This logically means that the more the load, the more strengthen the pool system is, because of the large energy invested into the pool system [9]. None of the remote communities around the Africa are physically or economically connected to an electric power grid through the conventional means of generating electricity. This is as a result of inability to coordinate resource together hence, the necessitated Electricity power pool system [10]. Electricity pooling is a concept of integrating several generated energies into one central usage. This can be intercontinentally agreed and regionally agreed but this design considered a small-scale pooling system for a remote community-based system that are made of renewable resources. These are more or less a market arrangement from agents that have generated enough and believe to have wasted a lot of resources. There are recorded cases of compulsory and voluntary pooling. The voluntary or net pool agent volunteer to buy and sell energy on bilateral agreement whereas the compulsory or gross pool requires that all the generating agents all apart from the small or the smallest ones will sell their output to the pool mangers at the pools agreed price [11].

\section{THE MODEL DESIGN TASK}

The prime objectives of this work are to develop an Android Applications Model for the Smart Micro-Grid Power Pool System Monitoring and Control Scheme with the Rationally Approach for Energy Sustainability encapsulation.

This prime target was achieved with the aid of the following sub-objectives: i. By designing a remotely enable soft touch screen operated Human Machine Interface to control the power pool system;

ii. By designing a power pool scheme for the five communities in Afikpo Local Government Area of the Ebonyi state;

iii. By designing a hybrid, optimize renewable energy for the five communities understudy considering their energy demand;

iv. By designing a system that is capable of handling the system resources with real-time data documentation, analysis and presentation.

\section{STATEMENT OF PROBLEM}

Wastage of Power supply has been a serious problem especially in some areas in Afikpo North, Ebonyi State namely; Afikpo, Amaziri, Enohia, Ozzia and Unwana. Their potential energy resources are left unharvested, even the harvested ones are used on a standalone basis. Lack of resources integrated scheme for a named community led to the wastage of power supply. In order to consistently provide steady power supply, the energy generated from the above communities are integrated for common usage. The developed system maintains steady power supply and provides energy at the same time with ability to ration the Generated supply, at a safer cost and eliminate wastage. The solution to this is development of the power pool monitoring and control system which ensures the control and also provide a monitoring medium for quality effectiveness and sufficiency of power supply.

\section{METHODOLOGY}

\subsection{Materials and Resources}

i. $\quad$ Software
Proteus
* Android studio
* Arduino ID
Sublime text
ii. Hardware $\quad$ Hardwa Uno (At mega 328)
* GSM Module (SIM900A)
Relay
*oltage Regulator LM7805
Lamps
Battery
Resistors
Current Sensor ASC 712
5.2 Methods

\subsection{Methods}




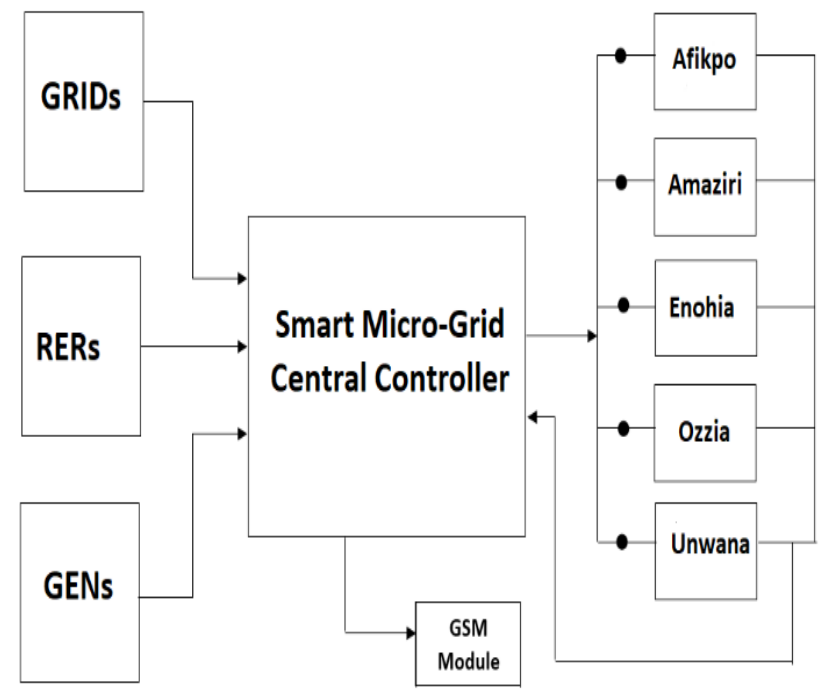

Figure 1: The block Representation of the Smart Microgrid Power Pool System

Figure 1 shows the formation of this smart Microgrid power pool system with hybridized three sources: The Grid; Renewable System: Wind Energy, Solar Energy and Biomass Energy and Alternative generating set. The Power Pool experimented design considers five different communities in Afikpo North Local Government area of Ebonyi State. The pool contributors are Afikpo, Amaziri, Enohia, Ozzia and Unwana

\subsection{The System Conceptual Design Model}

\subsubsection{Circuit diagram for the software implementation}

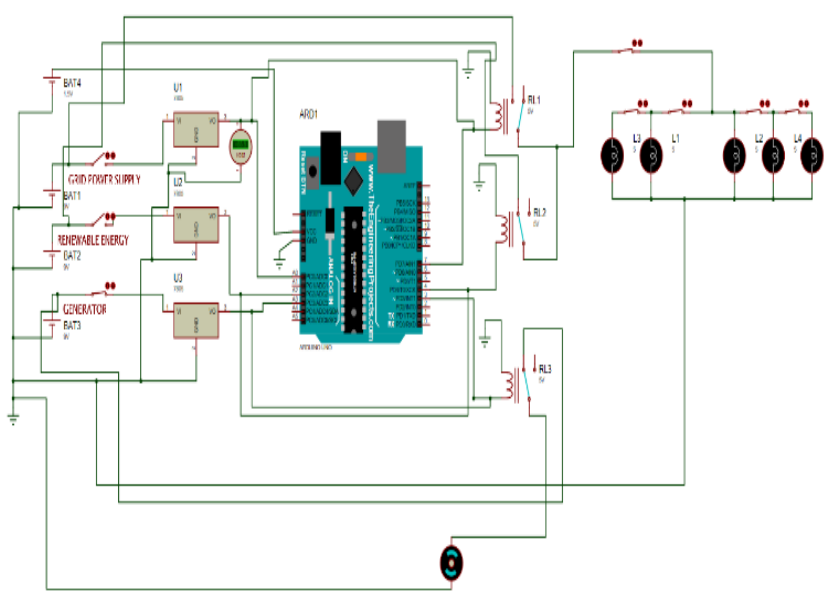

Figure 2: The Circuit diagram of the Smart Microgrid Power Pool System

Figure 2 shows how the microcontroller is configured to toggle between the three energy sources with priority to Grid resource followed by the renewable and to initiate the generator startup operation whenever the first two sources are OFF. This was achieved through simulation.

\subsection{Hardware Implementation}

The design hardware implementation was achieved using components assembly on bread board and later transfer to the Vero board and soldering process followed on making up the circuit to make sure that all components are permanently mounted.

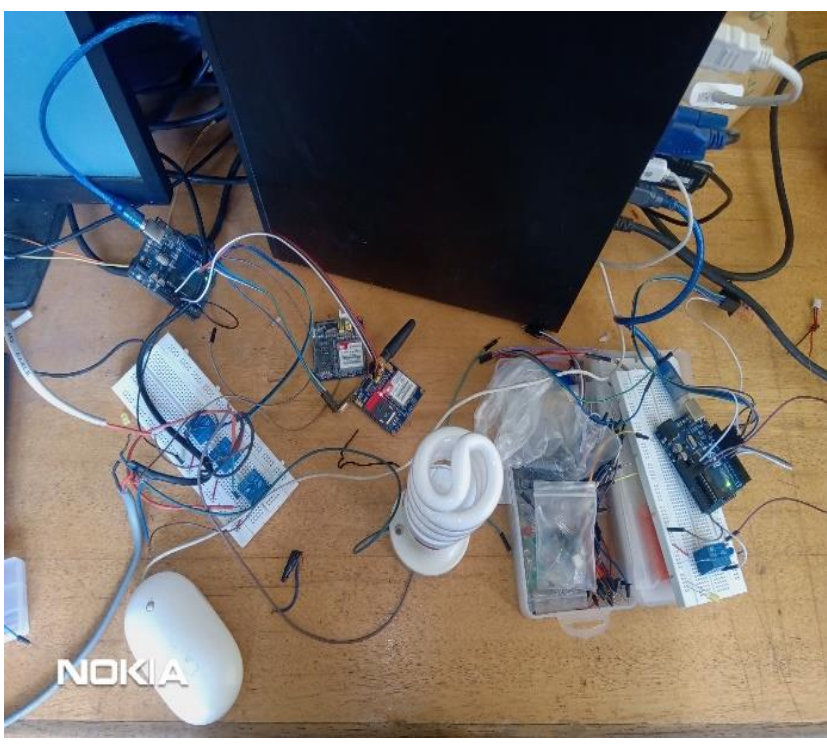

Figure 3: The Implementation Model for the Smart Microgrid Power Pool System

Figure 3 shows how the microcontroller is configured to toggle between the three energy sources with priority to Grid resource followed by the renewable and to initiate the generator startup operation whenever the first two sources are OFF. This was achieved through relay operation.

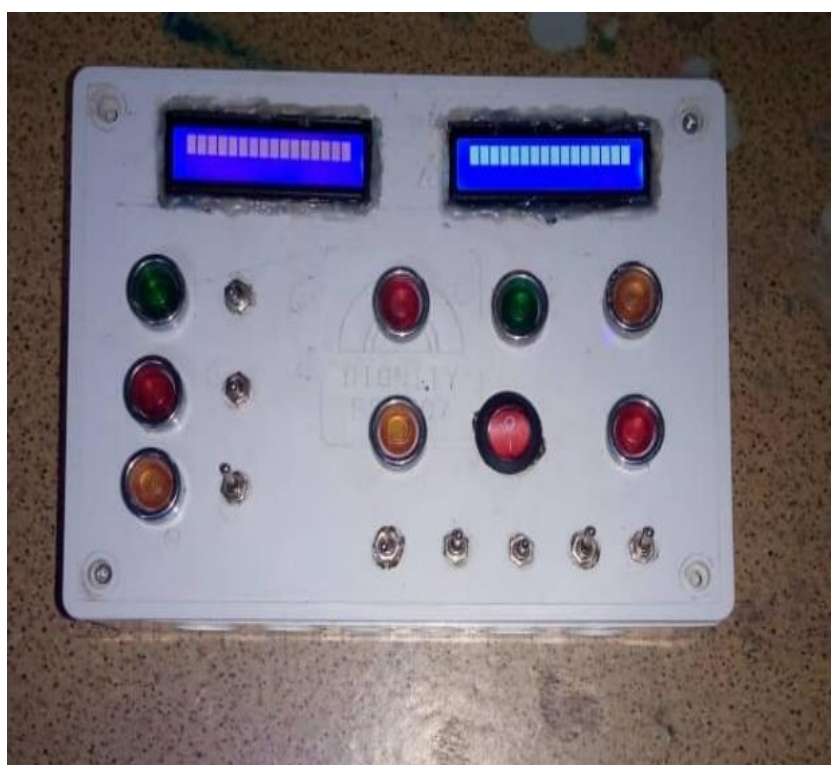

Figure 4: The Implemented hardware human machine interface Model for the Smart Microgrid Power Pool System

Figure 4 shows how the microcontroller is configured to toggle between the three energy sources with priority to Grid resource followed by the renewable and to initiate the generator startup operation whenever the first two sources are OFF. This was achieved through relay operation. The indicator shows how the five communities' benefit from the integrated energy resources.

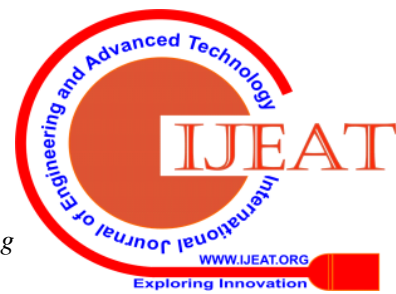




\subsection{Flow Chart}

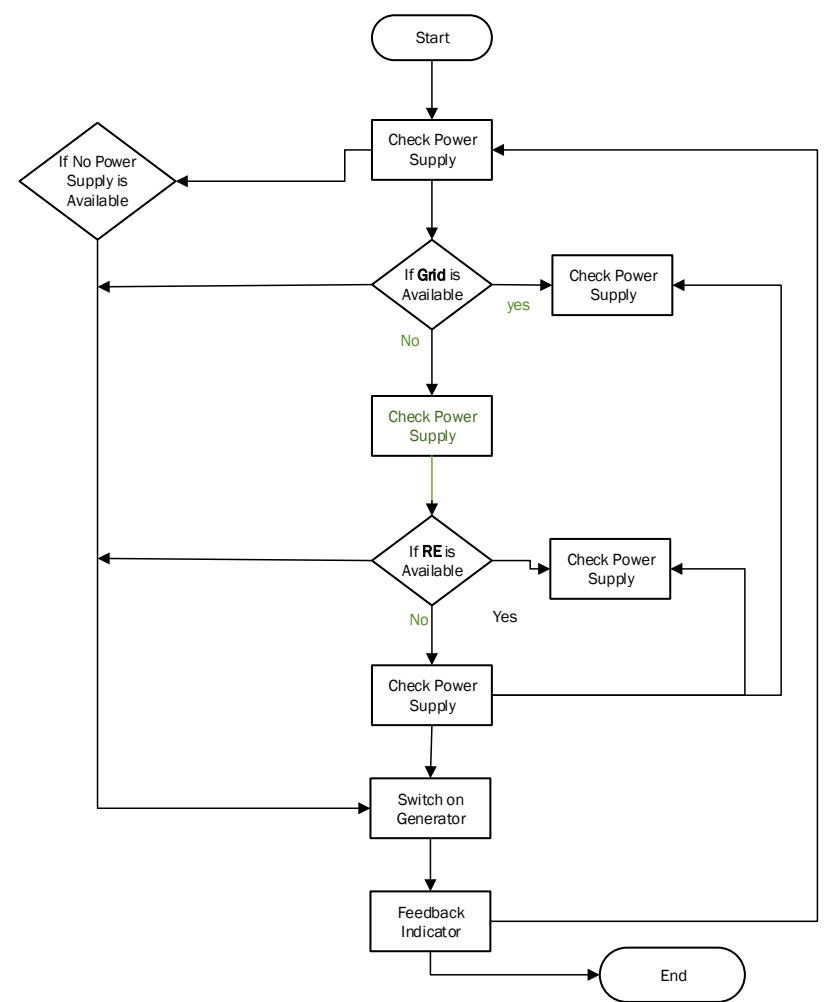

Figure 5: Flowchart of the Smart Microgrid Power Pool System

\section{PSEUDO-CODE}

Check Power Supply

If grid is available

Switch to grid

If $R E$ is available

Switch to Renewable Energy

If grid and Renewable Energy are not available

Switch to Generator

Else

Check Power Supply

\section{MOBILE APPLICATION INTERFACE DEVELOPMENT}

The remote-control interface is developed using Hypertext Mark-up Language (HTML), JavaScript and Cascading Style Sheets (CSS): HTML provide the overall outlook of the pool interface without any functionality given to the components of the pool interface, it allows for the arrangement of words and paragraphs on the interface; Cascading Style Sheets (CSS) provides several styles and colors used in designing the pool interface. It beautifies the interface making it eye-catching to the pool operator and the JavaScript gives functionality to the components of the interface. The components on the interface are buttons and switches. These buttons and switches are used to actuate the transfer of energy within the system. On the account of each energy transfer, JavaScript enables visible display of the device on the interface. The sign in and up interface for the operator are also designed.
VII. RESULTS DISCUSSION AND ANALYSIS

7.1 Mobile Application Interface Layout

\section{i. Sign up Interface results}

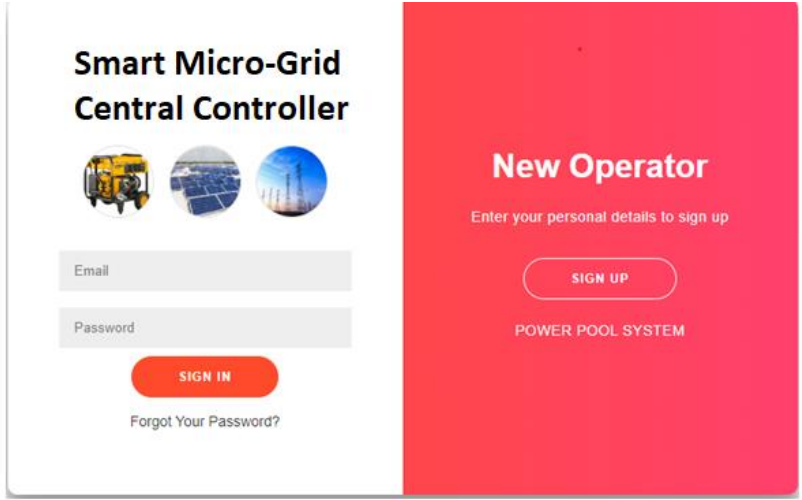

Figure 6: The Android sign up page for the Smart Microgrid Power Pool System

\section{ii. Soft-touch remote human machine Interface results}

With the layout of the mobile application, a user can control all the three sources of the energy, from grid, renewable energy and generator. The interface, which has a label and a switch on a card separated for each energy source. The user has control over all the sources and can choose to turn all sources off with a single click of the switch.

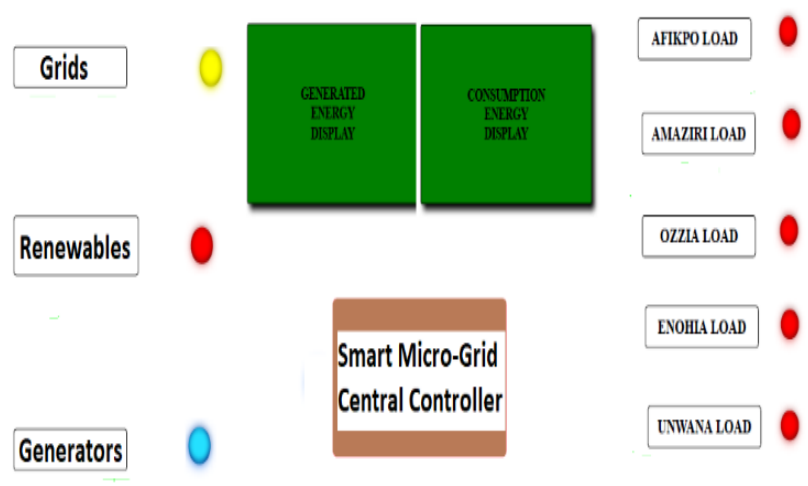

Figure 7: The Remote soft-touch interface for the Smart Microgrid Power Pool System

From figure 7, when the switches are ON, the Power supply $9 \mathrm{~V}$ is stepdown to $5 \mathrm{~V}$ using a 7805 Voltage Regulator which is now used to power the Microcontroller (ATMega 328). Then program uploaded to the Microcontroller from Arduino IDE will now control the relay, thereby closing and opening. Then supply is given to the load to the lamps arranged to represent the communities.

There are three relays, each relay is given to the Grid, Renewable Energy and Generator respectively. When the Grid relay is On, then the other two relays are tripped off. In the case of breakdown supply from the Grid, Renewable Energy or Generator acts as the backup supply to the load. Backup supply that is, battery will charge using Grid during normal operation. 
Thus, DC supply is given to the load without interruption in power supply by switching the relay signal from slave relay to the master relay.Thus, provide a continuous power supply to the load by means of any of the sources from those that are operating the load, (i.e., Grid, Renewable Energy and Generator automatically in the absence of any of the source)

Table1. Power supply results to the microcontroller

\begin{tabular}{llll}
$\begin{array}{lll}\text { Output } \\
\text { (Current }\end{array}$ & $\begin{array}{l}\text { Input } \\
\text { (voltage }\end{array}$ & $\begin{array}{l}\text { Output } \\
\text { (voltoge }\end{array}$ & $\begin{array}{l}\text { Input } \\
\text { [microcontraller] }\end{array}$ \\
\hline 12VDC & regulator) & regulator) & (Voc) \\
\hline
\end{tabular}

Table 1 shows the input status of the current sensor, voltage regulator input and output as well as input to the controller.

Table 2. Power supply Results to load in different communities

\begin{tabular}{|c|c|c|c|c|}
\hline $\begin{array}{l}\text { Power } \\
\text { Source }\end{array}$ & $\begin{array}{c}\text { Input [power source] } \\
\text { (VAC) }\end{array}$ & Switch Status & App Display & Load Status \\
\hline Grid & $220 \mathrm{~V}$ & ON & Grid & Bulb Light \\
\hline Grid & $220 \mathrm{~V}$ & OFF & No Power & No Light \\
\hline $\begin{array}{l}\text { Renewable } \\
\text { Energy }\end{array}$ & $220 \mathrm{~V}$ & ON & $\begin{array}{l}\text { Renewable } \\
\text { Energy }\end{array}$ & Bulb Light \\
\hline $\begin{array}{l}\text { Renewable } \\
\text { Energy }\end{array}$ & $220 \mathrm{~V}$ & OFF & NO Power & NO Light \\
\hline Generator & $220 \mathrm{~V}$ & ON & Generator & Bulb Light \\
\hline Generator & $220 \mathrm{~V}$ & OFF & No Power & No Light \\
\hline
\end{tabular}

In this research, a table 2 is created with three objects. These objects contain the grid, generator and renewable energy having a Boolean value of either true or false. The Boolean value is determined based on the active source which bears the true value, leaving the rest as false.

\section{iii. Database Result}

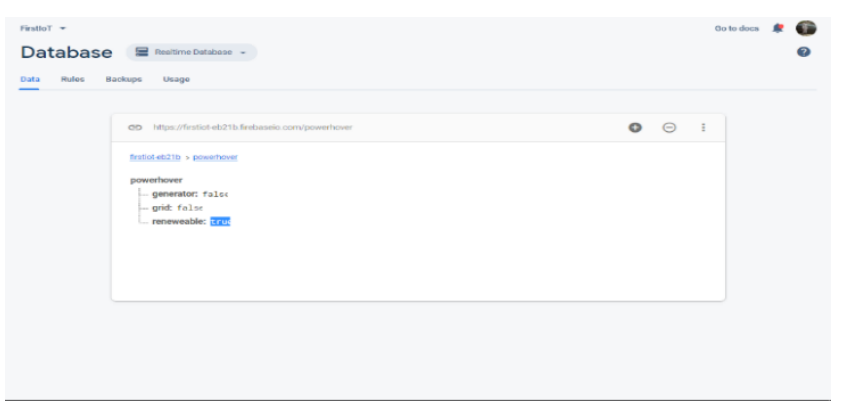

Figure 7: The Cloud storage database for the Smart Microgrid Power Pool System

Figure 7 is the Cloud Storage where both the generated and the consumption energy are documented for future use. The communication between the microcontroller and the mobile application interface are documented on cloud. Cloud Storage is built for app to store and serve user-generated content. It is the most suitable storage platform for mobile development data.

\section{CONCLUSIONS, CONTRIBUTION TO KNOWLEDGE AND RECOMMENDATION FOR FUTURE WORK}

The conceptual Android Applications Model for the Smart Micro-Grid Power Pool Monitoring and Control Scheme was developed. The Rational Approach for Energy Sustainability was achieved and serve as a formidable measure to monitor and control the system against energy wastage remotely. The proposed smart micro-grid integrated scheme with android enable operated soft-touch human machine interface for the remote monitoring and control of the hybrid power pool system with its load shedding capability for Energy Sustainability was achieved. The optimize hybridized renewable energy resources harvested from the abundant wind, sun, water and bio-resources with the grid and Generator sources from Afikpo North Local Government Area of Ebonyi State was put to use. Proteus was used in designing system circuitries for the control and monitoring of the power pool system to ascertain its behavior through simulation and Arduino IDE was used in developing monitoring and control algorithm for the system operation. The sublime text enables HTML, JAVA and CSS program was developed for the android applications. The design provides a remote operated touch screen Human Machine interface for the pool resources to be centrally managed thus, eliminating energy wastage. Five communities were selected for this demonstration. The results reveal that the android enable remote soft touch human machine interface facilitates optimal energy operation. Further research work should be tailored towards developing a similar scheme using same approach for up to 10 communities in the similar local government areas to face out energy sabotage.

\subsection{Contribution to knowledge}

The contribution made in this research work:

i. The Android Applications Model for the Smart MicroGrid Power Pool Monitoring and Control Scheme is the major contribution to the work.

ii. The Rational Approach for Energy Sustainability was achieved and serve as a formidable measure to monitor and control the system against energy wastage remotely.

iii. The Experimented smart micro-grid integrated scheme with android enable operated soft-touch human machine interface for the remote monitoring and control of the hybrid power pool system.

iv. The Cloud Storage where both the generated and the consumption energy are documented for future use was achieved.

v. Remote energy monitoring and control is another achievement.

\subsection{Recommendation for future Work}

The development of an Android Applications Model for the Smart Micro-Grid Power Pool System Monitoring and Control Scheme:

The Rationally Approach for Energy Sustainability witnesses the following hindrance which Further research work should be tailored towards:

i. Developing a similar scheme using with the same approach for up to 10 communities in the similar local government areas to face out energy sabotage.

\subsection{Conclusion}


ii. Zigbee network should added for wider coverage.

iii. Community load assessment scheme should be incorporated.

\section{ACKNOWLEDGMENT}

My profound gratitude goes to the Almighty God for giving me the strength and wisdom to execute this research work despite all challenges and to my Mentors, Engr. Prof D.O.Dike ; Engr. Dr. Matthew Olubiwe and Engr. Dr. Judekennedy Obichere, I say thank you for your professional guidance that provided a foundation for research action to thrive successful.

\section{REFERENCES}

1. S. M. S. Siddiquee, M. S. Alam, M. K. Islam, M. H. Reza, and M. Al Arafat, "Optimized hybrid renewable energy system for efficien industrial electrification," 2nd Int. Conf. Electr. Eng. Inf. Commun. Technol. iCEEiCT 2015, vol. 2, no. 5, pp. 1-20, 2015.

2. C. Xing and D. M. Isaacowitz, "Assessment of Power -Pooling Arrangements in Africa," Economic Commission for Africa, vol. 30, no. 3, pp. 243-250, 2004

3. T. Haines and F. Joyce, "Raspberry Pi Human Machine Interface and Control System for an Electromagnet Water Filter," Proc. Annu. Mont. Tech Electr. Gen. Eng. Symp., vol. 19, no. April 2017, p. 47, 2017.

4. N. Lu and L. Yi, "Combined programming of labVIEW and simulink to simulate a hybrid energy power generation system," Int. J. Simul. Syst. Sci. Technol., vol. 17, no. 27, pp. 28.1-28.6, 2016.

5. P. N. Biskas, D. I. Chatzigiannis, and A. G. Bakirtzis, "Market coupling feasibility between a power pool and a power exchange," Electr. Power Syst. Res., vol. 104, no. November, pp. 116-128, 2013.

6. M. Ghofrani and N. N. Hosseini, "Optimizing Hybrid Renewable Energy Systems: A Review," in Sustainable Energy - Technological Issues, Applications and Case Studies, no. 2016, 2017, pp. 161-175.

7. B. Bhandari, K.-T. Lee, G.-Y. Lee, Y.-M. Cho, and S.-H. Ahn, "Optimization of hybrid renewable energy power systems: A review," Int. J. Precis. Eng. Manuf. Technol., vol. 2, no. 1, pp. 99-112, 2015.

8. S. Ashok, "Optimised model for community-based hybrid energy system," Renew. Energy, vol. 32, no. 7, pp. 1155-1164, 2007.

9. H. Haroonabadi and H. Barati, "Generation reliability assessment in power markets using MCS and neural networks," Int. Rev. Model. Simulations, vol. 4, no. 6, pp. 3098-3103, 2011.

10. Y. Sawle, S. C. Gupta, and A. K. Bohre, "PV-wind hybrid system: A review with case study," Cogent Eng., vol. 3, no. 1, pp. 1-31, 2016.

11. E. Onaiwu, "How Does Bilateral Trading Differ From Electricity Pooling?," in University of Dundee, 2010, pp. 1-12.

\section{AUTHORS PROFILE}

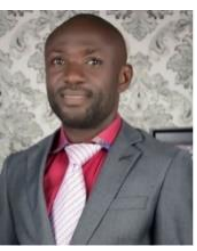

Engr. Kufre Esenowo Jack received the Master of Science (MSc) Degree in Applied Instrumentation and control from Glasgow Caledonian University, Scotland, United Kingdom in 2014. He received a Bachelor of Engineering Degree (B. Eng) in Electrical/Electronic Engineering from University of Port Harcourt, Rivers State, Nigeria in 2013. He also received a Higher National Diploma (HND) in Electrical/Electronic Engineering Technology and majored in Electrical Power and Machines from Petroleum Training Institute, Effurun, Delta State, Nigeria in 2005 and also received National Diploma (ND) in Electrical/Electronic Engineering Technology from The Polytechnic Calabar, Cross River State, Nigeria in 2001.From 2009 to 2018, he works with Akanu Ibiam Federal Polytechnic Unwana, Ebonyi State, Nigeria as an Academic Technologist and later as a lecturer in Electrical/Electronic Engineering Technology Department. Presently he is a lecturer in Mechatronics Engineering Department, Federal University of Technology Minna, Niger State, Nigeria. His current research interest is applicable in Renewable Energy System Control, Sensors and instrumentation design, Mechatronics System design, Intelligent Control system development, Robotics and Automation. He has coauthored many international and local papers on Automation, Renewable Energy and Intelligent Control Systems, coauthor of a book on a Control Systems, Measurement and Instrumentation, Programmable Logic Controllers and has taught a number of courses in Electrical Engineering, Electronics Engineering, Instrumentation and Control
Engineering, Mechanical System Vibrations and Mechatronics Engineering within the years of his experience.

Registered and practicing Engineer certified by the Council for the Regulation of Engineering in Nigeria (COREN), Member, International Association of Engineers (IAENG), Member, the Institution of Engineering and Technology (IET) United Kingdom, Member Nigeria Society of Engineers (MNSE) and Graduate Member, Measurement \& Control IEEE amongst others.

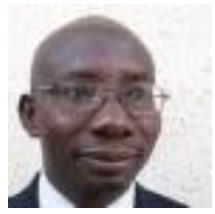

Engr. Prof. Damian Obioma Dike, a Professor in the Electrical and Electronic Engineering Department, Federal University of Technology Owerri (FUTO) Nigeria. He receives his doctoral degree from Tennessee Technological University, USA in 2008; M. Sc. Electrical Engineering (Power System Option), FUT Owerri, 2002 and B. Eng, Electrical and Electronic Engineering, FUT Owerri, 1995. He currently also serves as the University Alumni Relations Officer, FUTO. He worked with Cummins Inc (Power Generation) USA as a Senior Project Engineer from 2008 to 2010, where he designed and supervised the execution of 53 low and medium voltage paralleling system projects. At FUTO, he leads the electrical power and embedded systems research team (EPERT). He also serves as a coordinating consultant engineer to JENCEL Consults limited.

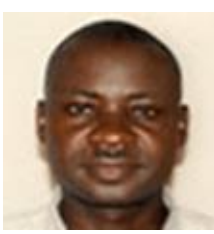

Engr. Dr. Olubiwe Matthew , is a Senior Lecturer in the deparpment of Electrical and Electronic Engineering, Federal University of Technology Owerri, Imo State, Nigeria. He receives his Ph.D in Power System Engineering (Machine \& Drives) from Federal University of Technology, Owerri in 2015, Master of Engineering Degree (M.ENG) in Machine and Power, University of Port Harcourt, Port Harcourt in 2004 and B. Eng in Electrical and Electronic Engineering, University of Port Harcourt in 1997. He receives Advance HSE Certificate course (0016930) and Basic HSE Certificate Course (30658). He worked with Living Worth Global Services Nig. Limited between 1998 to 2000; COCACC Resources Nig. Limited between 2004 to 2006 and Netco Dietsmann Oil and Gas between 2006 to 2007. He has published so many international researched journal papers on power system , machine and drives and control systems researched papers.

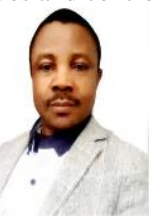

Engr. Dr. Jude K. C. Obichere received the B.Eng and M.Eng degrees in Electrical and Electronic Engineering (Power Systems \& Control) from University of Port Harcourt, Nigeria, in 1992 and 2004 respectively. He also obtained his $\mathrm{PhD}$ in Control Engineering and Renewable Energy in 2016 at Northumbria University, Newcastle Upon Tyne, United Kingdom where he also worked as an Associate Lecturer. He worked for so many years in the Oil \& Gas Industry on Drilling Mud Solids Control \& Waste Management and VSP Seismic. He is a Consultant in the Oil \& Gas and Director in so many companies. He is currently working as a Senior Lecturer with the Department of Mechatronics Engineering, Federal University of Technology Owerri (FUTO), and an Adjunct Senior Lecturer with the Electrical and Electronics Engineering, Federal University of Petroleum Resources Effurun (FUPRE), Nigeria. He has received Merit Award and Best Paper Award for his outstanding quality research papers, from the World Congress on Engineering and Computer Science (WCECS) of the International Association of Engineers (IAENG). He has co-authored 3 book chapters published in Springer and World Scientific and published over 15 international journals and conference papers. He serves as a Reviewer in so many International Journals in Science and Engineering such as African Journal of Engineering Research (AJER), Elsevier, Optical Material Express, Scientia Iranica (SCI), SciTecnol etc. He is a member of the Nigerian Society of Engineers (MNSE), Council for the Regulation of Engineering in Nigeria (COREN), International Association of Engineers (IAENG), The Institution of Engineering and Technology (IET) United Kingdom, European Energy Centre (MEEC) and Power \& Energy Society Member of IEEE amongst others.His research interests include in Electrical Machines \& Drives, Power Systems, Control and Renewable Energy. 